\title{
Advanced oxidation protein products trigger apoptosis and block epithelial-to-mesenchymal transition in crypt epithelial cells
}

\author{
YU ZHENG $^{1}$, JIN-TAO ZENG ${ }^{2}$, XIANG-YU WANG ${ }^{1}$, HAI-XIAO HUANG ${ }^{1}$, \\ LIANG-XIANG HUANG $^{1}$ and CHANG-QING ZENG ${ }^{1}$ \\ ${ }^{1}$ Department of Gastrointestinal Surgery, Fujian Provincial Hospital, \\ Provincial Clinical Medical College of Fujian Medical University, Fuzhou, Fujian 350001; \\ ${ }^{2}$ Basic Medical College, Chengde Medical University, Chengde, Hebei 067000, P.R. China
}

Received May 28, 2020; Accepted September 22, 2020

DOI: $10.3892 /$ etm.2021.10317

\begin{abstract}
Advanced oxidation protein products (AOPPs) are uremic toxins. The present study aimed to investigate the effects of AOPPs on the epithelial mesenchymal transition (EMT) and apoptosis of rat crypt epithelial cells, and to assess the signaling pathways involved. The oxidized rat serum albumin was obtained by sodium hypochlorite modification as AOPPs, and the rat serum albumin (RSA) without sodium hypochlorite modification was set as the control. Different concentrations of AOPPs or RSA were incubated with rat crypt epithelial cells (IEC-6 cells). After culturing for 48 and $72 \mathrm{~h}$, apoptosis was detected by flow cytometry. IEC- 6 cells were divided into three groups: A normal group, an AOPPs group and an RSA group. Three groups of cells were collected following treatment for $2 \mathrm{~h}$, and the phosphorylation levels of Akt and p65 NF- $\kappa \mathrm{B}$ were detected by western blotting. After $72 \mathrm{~h}$ of treatment, the cells were collected and the apoptotic rate was detected by flow cytometry. The expression of EMT-related proteins was detected by reverse transcription-quantitative polymerase chain reaction and western blotting. The apoptotic rate of IEC-6 cells increased with the concentration of AOPPs, and the apoptotic rate of the AOPPs group was higher than that of the RSA group. The expression of fibronectin, snail, slug and collagen I in the AOPPs group was lower than that in the RSA group, while the expression of E-cadherin was not significantly different between the two groups. In addition, the expression of fibronectin, snail, slug and collagen I genes in the AOPPs-treated group was equal to or lower than that in the normal group. Compared with the normal group, the Akt
\end{abstract}

Correspondence to: Dr Liang-Xiang Huang or Dr Chang-Qing Zeng, Department of Gastrointestinal Surgery, Fujian Provincial Hospital, Provincial Clinical Medical College of Fujian Medical University, 134 Eastern Road, Fuzhou, Fujian 350001, P.R. China

E-mail: hlxhuanglx@163.com

E-mail: changqingzeng@163.com

Key words: advanced oxidation protein products, IEC-6, epithelial-mesenchymal transition, Akt, P65 phosphorylation level was decreased and the p65 phosphorylation level was increased in the AOPPs- or RSA-treated groups. Compared with the AOPPs-treated group, Akt and p65 phosphorylation levels in RSA-treated group were slightly higher. In conclusion, AOPPs trigger apoptosis and inhibit the EMT of rat crypt epithelial cells, which may be associated with the inhibition of Akt phosphorylation and the promotion of p65 phosphorylation.

\section{Introduction}

Advanced oxidation protein products (AOPPs) are uremic toxins created during oxidative stress through the reaction of plasma proteins with chlorinated oxidant. The AOPPs were found in the plasma of patients with chronic renal failure in 1996 by Witko-Sarsa et al (1). AOPPs may serve as a novel marker of oxidative stress in uremia and postmenopausal osteoporosis (2). It was reported that AOPPs may induce the respiratory burst of neutrophils and monocytes, and the damage of monocytes to produce cytokines and endothelial cells, which is associated with disorders of immune function and atherosclerosis in patients with chronic renal failure (3-7).

Inflammatory bowel disease (IBD) is a common gastrointestinal disease, which is difficult to treat. The intestinal tract in a chronic inflammatory state often leads to intestinal epithelial damage, which affects the quality of life of patients (8). The serum level of AOPPs was markedly increased in patients with IBD (9). AOPPs have been reported to deposit in the intestinal lesions of patients with IBD and to promote the synthesis of type I collagen in intestinal epithelial cells (10). These studies suggest a correlation between AOPPs and intestinal epithelial lesions. However, in-depth studies regarding this are lacking.

Crypt epithelial cells in the intestinal tract have a high potential to proliferate and differentiate, and serve a major role in repairing the intestinal epithelium (11). In the present study, a sodium hypochlorite modified method was used to produce oxidized rat serum albumin (RSA) (12), which mimicked the effects of AOPPs. The present study aimed to investigate the effects of AOPPs on apoptosis and epithelial mesenchymal transition (EMT) in rat crypt epithelial cells. Additionally, the potential signaling pathways were determined. 


\section{Materials and methods}

Preparation of AOPPs. AOPPs were prepared as previously described (12,13). In brief, 100 mg RSA (EY-D0667; Yiyan Biological Technology) was dissolved in $5 \mathrm{ml}$ sterile water, with $73.1 \mu 110 \%$ sodium hypochlorite under stirring conditions at room temperature for $30 \mathrm{~min}$, and dialyzed at $4^{\circ} \mathrm{C}$ in PBS for $24 \mathrm{~h}$. The dialysate was changed every two hours, filtered and sterilized, and kept at $-20^{\circ} \mathrm{C}$ for use. RSA without sodium hypochlorite modification was weighed and dissolved in $5 \mathrm{ml}$ sterile water, filtered and sterilized, and stored at $-20^{\circ} \mathrm{C}$ as a control.

Treatment with AOPPs and determination of apoptosis. Crypt epithelial IEC-6 cells were obtained from Bena BIOTECH (bncc338482) and cultured in Dulbecco's modified Eagle's medium supplemented with 10\% FBS (HyClone; GE Healthcare Life Sciences) in a $37^{\circ} \mathrm{C}$ incubator with $5 \% \mathrm{CO}_{2}$.

The optimal concentrations of AOPPs were selected based on the aforementioned experiments. IEC-6 cells were divided into three groups: Normal control, AOPPs and RSA groups. Three groups of cells were collected after $2 \mathrm{~h}$ of treatment, and the phosphorylation level of p65 in Akt and NF- $\mathrm{kB}$ was detected by western blotting. After $72 \mathrm{~h}$ of treatment, the cells were collected and the apoptotic rate was detected by flow cytometry. The expression of E-cadherin, fibronectin, snail, slug and collagen I associated with EMT was detected by reverse transcription-quantitative polymerase chain reaction (RT-qPCR) and western blotting.

The cells in the exponential growth phases were cultured in a six-well plate. Following treatment with different concentrations of AOPPs (100, 200 or $400 \mu \mathrm{g} / \mathrm{ml})$ or RSA $(100,200$ or $400 \mu \mathrm{g} / \mathrm{ml}$ ) for 48 or $72 \mathrm{~h}$, the cells were collected. The apoptotic rate was determined by flow cytometry using Annexin V-APC and 7-aminoactinomycin D (7-AAD). The supernatant was discarded, and the cells were washed twice with $1 \mathrm{ml}$ PBS for each well. A total of $200 \mu \mathrm{l}$ trypsin with EDTA was added into each well in a $37^{\circ} \mathrm{C}$ incubator for digestion. The cells were collected following centrifugation $(2,000 \mathrm{x} \mathrm{g}$ for $3 \mathrm{~min}$ at room temperature). A total of $3 \mu \mathrm{l}$ Annexin V-APC and $5 \mu \mathrm{l}$ 7-AAD were added to each tube respectively and incubated at room temperature in the dark for $10 \mathrm{~min}$. Subsequently, the apoptotic rate was detected using a flow cytometer.

$R T-q P C R$. Total RNA was extracted from each group of cells using an Ultrapure RNA Extract kit (CW0581M; CWBio). After RNA was extracted, cDNA was synthesized according to the reverse transcription kit (CW2569M; CWBio). cDNA was used as a template and detected on the fluorescence quantitative PCR using UltraSYBR Mixture (CW0957M; CWBio). The thermocycling conditions were as follows: Initial denaturation at $95^{\circ} \mathrm{C}$ for $10 \mathrm{~min}$, followed by 40 cycles of PCR at $95^{\circ} \mathrm{C}$ for $10 \mathrm{sec}, 60^{\circ} \mathrm{C}$ for $30 \mathrm{sec}$ and $72^{\circ} \mathrm{C}$ for $30 \mathrm{sec}$. The expression levels of E-cadherin, fibronectin, snail, slug and collagen were detected by qPCR in each group, which were normalized to GAPDH, as previously described (14) using the the $2^{-\Delta \Delta C q}$ method (15). The primers are listed in Table I.

Western blotting. Protein was extracted using RIPA buffer (89901; Thermo Fisher Scientific, Inc.) and the concentration was determined using the bicinchoninic acid method (CW0014S; CWBio). The proteins were denatured at $100^{\circ} \mathrm{C}$. A total of $20 \mu \mathrm{g}$ protein in each group was run on $10 \%$ sodium dodecyl sulfate-polyacrylamide gels and transferred onto nitrocellulose membranes. The membranes were then blocked with 5\% skimmed milk for $30 \mathrm{~min}$ at room temperature, followed by an incubation with the primary antibodies at $4^{\circ} \mathrm{C}$ overnight. The primary antibodies used were against anti-E-cadherin (1:500; AF0131; Affinity Biosciences), anti-Fibronectin (1:1,000; ab32419; Abcam), anti-Snail (1:500; AF603; Affinity Biosciences), anti-Slug (1:500; AF4002; Affinity Biosciences), anti-Collagen I (1:500; AF7001; Affinity Biosciences), anti-pan-Akt (1:500; ab8805; Abcam), anti-NF-кB p65 (1:1,000; bs-0465R; BIOSS), anti-phospho-NF-кB p65 (1:500; AF2006; Affinity) and anti-phospho-Akt (1:500; bs-2720R; BIOSS). Subsequently, the membrane was incubated with a horseradish peroxidase (HRP)-labeled goat anti-rabbit IgG secondary antibody (cat. no. 65-6120; Thermo Fisher Scientific, Inc.) and a HRP-labeled goat anti-mouse $\operatorname{IgG}$ secondary antibody (cat. no. 31430; Thermo Fisher Scientific, Inc.) at room temperature for 1-2 h. Enhanced chemiluminescence solution (cat. no. SW2010-1; Beijing Solarbio Science \& Technology Co., Ltd.) was added to the membrane and exposed in the gel imaging system. The gray values of antibody bands were analyzed by 'Quantity one' software v4.6 (Bio-Rad Laboratories, Inc.).

Statistical analysis. All data were statistically analyzed using SPSS 19.0 (IBM Corp.) and significant differences were determined by one-way analysis of variance, followed by Tukey's post hoc tests. $\mathrm{P}<0.05$ was considered to indicate a statistically significant difference.

\section{Results}

AOPPs promotes the apoptosis of IEC-6 cells. The apoptotic rates of IEC- 6 cells following treatment with AOPPs or RSA for 48 and $72 \mathrm{~h}$ are shown in Fig. 1. The apoptotic rate of IEC-6 cells treated with AOPPs increased with the increased concentration of AOPPs for $48 \mathrm{~h}$ (from 8.5-12.9\%), while treatment with similar concentrations of RSA for $48 \mathrm{~h}$ did not cause apoptosis in IEC-6 cells (from 6.5 to $8.1 \%$; Fig. 1A and C). By contrast, treatment with $400 \mu \mathrm{g} / \mathrm{ml}$ AOPPs or RSA for $72 \mathrm{~h}$ significantly induced apoptosis in IEC-6 cells (compared with the normal group, $\mathrm{P}<0.05$ ). Furthermore, the apoptotic rate in the AOPPs treatment group was higher than that in the RSA treatment group $(\mathrm{P}<0.05$; Fig. $1 \mathrm{~B}$ and $\mathrm{D})$.

AOPPS inhibits the EMT of rat crypt epithelial cells. EMT-related protein expression was detected in rat crypt epithelial cells treated with AOPPs and RSA for $72 \mathrm{~h}$. The protein expression of fibronectin, snail and slug in the AOPPs group was lower than that in the control and RSA groups, while the expression of E-cadherin was promoted by treatment with AOPPs (vs. normal, $\mathrm{P}<0.05$; Fig. $2 \mathrm{~A}$ and B). Collagen I was not significantly different among the groups (Fig. 2A and B). The mRNA expression of fibronectin, snail, slug, E-cadherin and Collagen I was also detected (Fig. 2C). Consistent with the protein expression results, AOPPs decreased slug expression and promoted E-cadherin expression, compared with the 
Table I. Primer sequences of the genes.

Gene

Primer sequence $\left(5^{\prime}-3^{\prime}\right)$

Primer length, Product length, bp

E-cadherin forward

E-cadherin reverse

Fibronectin forward

Fibronectin reverse

Snail forward

Snail reverse

Slug forward

Slug reverse

Collagen I forward

Collagen I reverse

GAPDH forward

GAPDH reverse
FACTCTTCTCCTGGTCCTGTCA CTCTAAGTCCTTTCTTGGTTGC CTATTTACCAACCCCAGACCC GCATTCCCACAGAGTAGACCA ATGAGGACAGTGGCAAAAGC CGGGAAGGCAATGAAGG CAACTACAGCGAACTGGACAC ACACGCCCCAAAGATGAG GCCTGAGCCAGCAGATTGA GCTTCTTCTCCTTGGGGTTT CAACGGGAAACCCATCACCA ACGCCAGTAGACTCCACGACAT

21

21

22

21

21

20

17

21

18

19

20

20

20

bp

$\begin{array}{lc}240 & 58.4 \\ 87 & 58.6 \\ 113 & 56.9 \\ 207 & 58.2 \\ 258 & 58.9 \\ 96 & 62\end{array}$

A
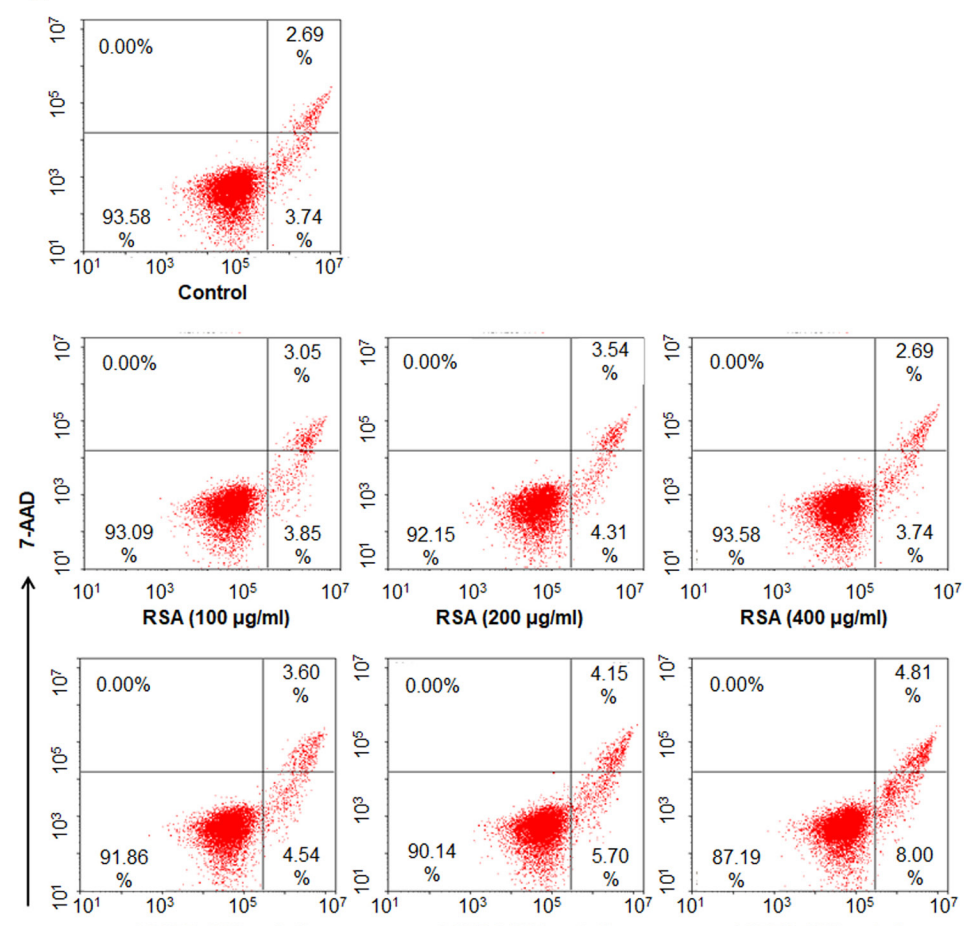

AOPPS $(100 \mu \mathrm{g} / \mathrm{ml})$ $\longrightarrow$ Annexin V-APC

c

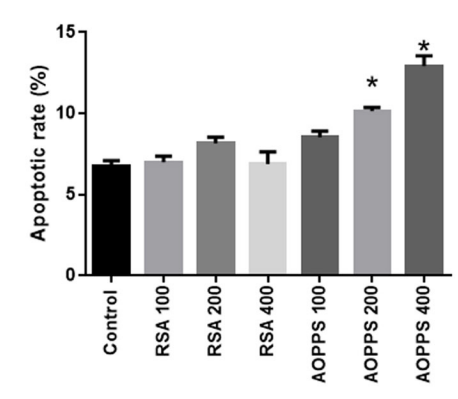

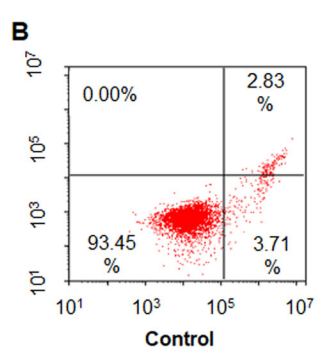
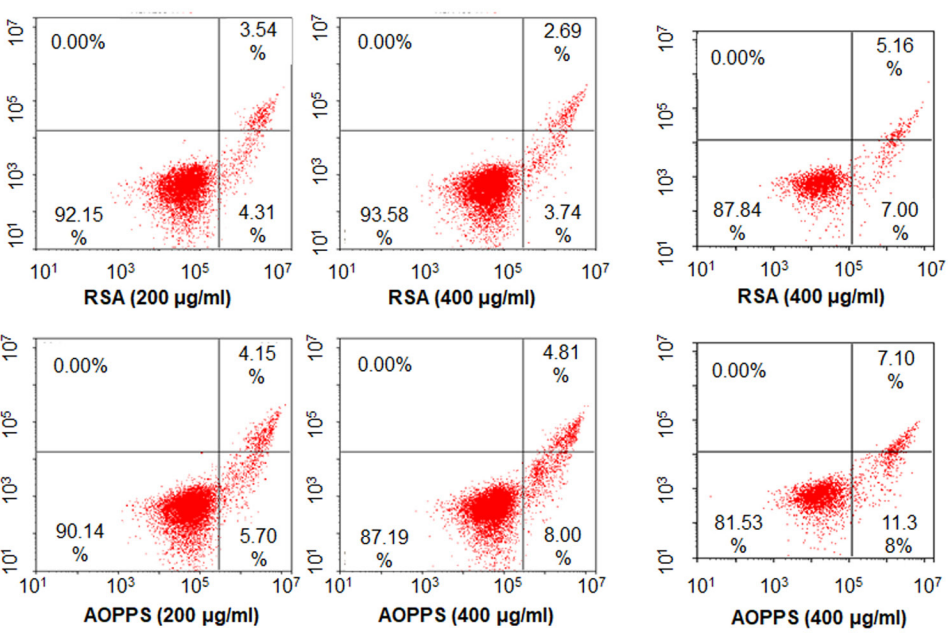

Figure 1. AOPPs promoted the apoptosis of IEC-6 cells. (A) IEC-6 cells were treated with AOPPs or RSA for 48 h; representative images of flow cytometry. (B) IEC-6 cells were treated with AOPPs or RSA for $72 \mathrm{~h}$; representative images of flow cytometry. (C) Quantitative data of the apoptotic rate in IEC-6 cells treated with AOPPs or RSA for 48 h. (D) Quantitative data of the apoptotic rate in IEC- 6 cells treated with AOPPs or RSA for $72 \mathrm{~h}$. ${ }^{*} \mathrm{P}<0.05 \mathrm{vs}$. control; ${ }^{\#} \mathrm{P}<0.05$ vs. RSA. AOPPs, RSA. 
A

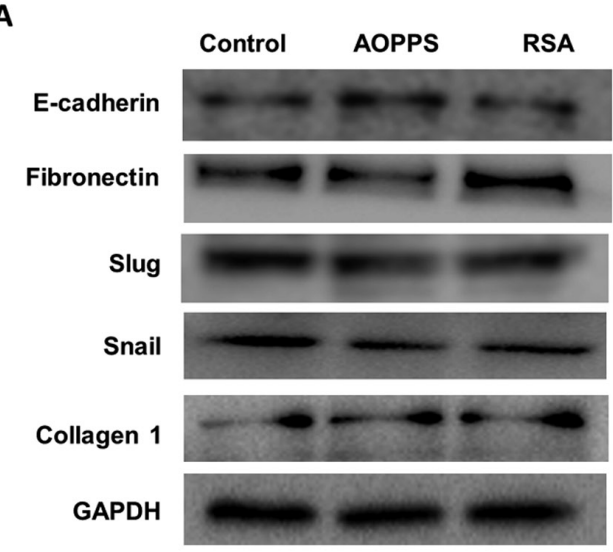

C
B

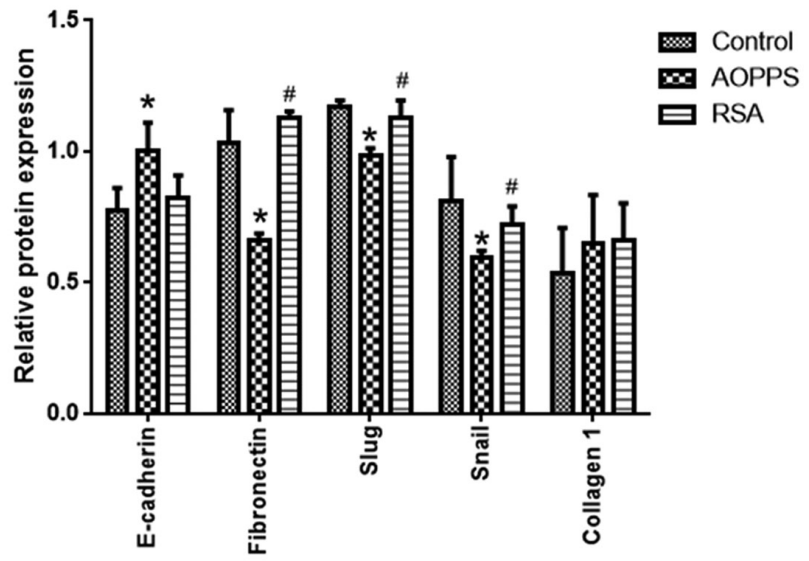

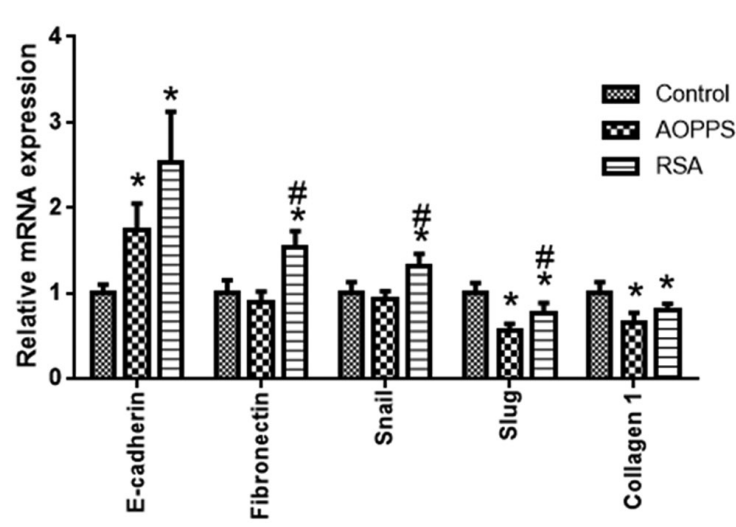

Figure 2. AOPPs inhibited the EMT of rat crypt epithelial cells. (A) EMT-related protein expression; representative blots of the related proteins. (B) Quantitative data of the related protein expression. (C) EMT-related gene expression at mRNA level. " $\mathrm{P}<0.05$ vs. control; " $\mathrm{P}<0.05$ vs. AOPPs. AOPPs; EMT, epithelial-mesenchymal transition.
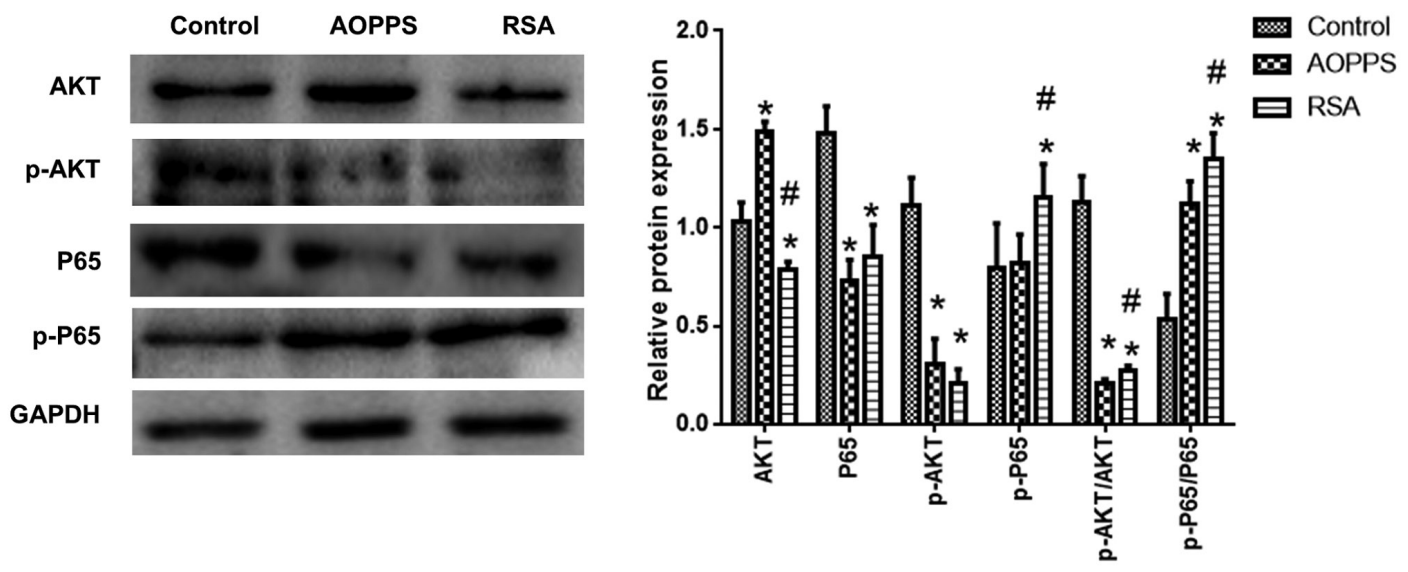

Figure 3. AOPPs reduced phosphorylation of Akt and promoted the phosphorylation of P65. "P $<0.05$ vs. control; ${ }^{*} \mathrm{P}<0.05$ vs. AOPPs. AOPPs.

control groups. By contrast, AOPPs did not affect fibronectin and snail expression. RSA treatment promoted E-cadherin, fibronectin and snail expression, but decreased slug and collagen I expression (Fig. 2C).

AOPPs decreases the phosphorylation of Akt and promotes the phosphorylation of P65. The phosphorylation of Akt and NF- $\mathrm{KB}$ levels was detected. Compared with the control group, Akt phosphorylation levels in the AOPPs- and RSA-treated groups was decreased, while NF-p $65 \kappa \mathrm{B}$ phosphorylation was increased (vs. normal, $\mathrm{P}<0.05$ ). Akt and $\mathrm{p} 65$ phosphorylation in the RSA treatment group was slightly higher than that in the AOPPs treatment group (Fig. 3).

\section{Discussion}

The results of the present study suggested that AOPPs promoted apoptosis and prohibited EMT in crypt epithelial 
cells. Furthermore, it was demonstrated that AOPPs likely exhibited these functions through the Akt and NF- $\kappa \mathrm{B}$ signaling pathways. The present study reported novel effects of AOPPs on the biological activities of crypt epithelial cells.

It has been reported that AOPPs may increase reactive oxygen species (ROS) production in IEC-6 cells, activate the c-JNK signaling pathway, and induce apoptosis in IEC-6 cells (16). The results of the present study suggested that the apoptotic rate of IEC- 6 cells treated with AOPPs increased with the increasing concentration of AOPPs over a $48 \mathrm{~h}$ period. By contrast, similar concentrations of RSA treated for $48 \mathrm{~h}$ did not cause apoptosis in IEC-6 cells. Moreover, the apoptotic rate of AOPPs- or RSA-treated cells at $72 \mathrm{~h}$ increased compared with that of $48 \mathrm{~h}$, and the apoptotic rate of the AOPPs treatment group was higher than that of RSA treatment group. It can be inferred that AOPPs deposited in intestinal lesions may inhibit the recovery of intestinal epithelial cells, and serum albumin alone may promote the apoptosis of intestinal epithelial cells under the conditions of IBD and other diseases $(17,18)$. Therefore, it can be concluded that the common symptoms of IBD, intestinal hemorrhage, may worsen the disease.

AOPPs may activate the TGF- $\beta /$ Smad signaling pathway by inducing ROS, which leads to the upregulation of EMT in liver cells (19). It has also been found that AOPPs may upregulate the inflammatory response of osteoblast-like cells and activate the NF- $\mathrm{NB}$ signaling pathway, in order to inhibit the proliferation and differentiation of osteoblast-like cells (20). The phosphatidylinositol-3-kinase (PI3K)/Akt signaling pathway is one of the main pathways regulating cell proliferation and apoptosis (21), and Akt phosphorylation level is a key indicator reflecting the activity of the PI3K/Akt signaling pathway $(22,23)$. NF- $\mathrm{KB}$ is composed of P50 and p65 proteins, and p65 phosphorylation level is a key index reflecting the activity of the NF- $\kappa \mathrm{B}$ signaling pathway $(24,25)$. The present study reported that the Akt phosphorylation level decreased and the p65 phosphorylation level increased in AOPPs- or RSA-treated cells, which corresponded with the increase in the apoptotic rate. However, although the apoptotic rate of cells in the RSA treatment group was lower, the phosphorylation level of p65 was higher than that in AOPPs treatment group, which suggested that RSA may activate the inflammatory response associated with the NF- $\mathrm{NB}$ signal pathway of intestinal epithelial cells, and the apoptosis of intestinal epithelial cells induced by AOPPs was not only controlled by the NF- $\mathrm{B}$ signaling pathway.

EMT refers to the process through which epithelial cells change into mesenchymal cells. The mesenchymal cells produced by EMT are mainly fibroblasts; therefore, EMT is an important mechanism leading to tissue fibrosis $(26,27)$. In the present study, the effects of AOPPs on the EMT of intestinal epithelial cells were analyzed by detecting the expression of E-cadherin, fibronectin, snail, slug and collagen I $(28,29)$. The results of the present study suggested that the expression of E-cadherin in IEC-6 cells treated with AOPPs was higher, while fibronectin was lower than that in the control group. These data indicated that AOPPs decreased the EMT of IEC-6 cells. In addition, transcription factors promoting EMT phenotype transformation, including snail and slug, were also lower in APPPs-treated cells. These results further suggested that AOPPs prohibited EMT, unlike RSA. The present study reported that the mRNA expression of EMT-related genes was inconsistent with the protein expression. These data suggested that AOPPs regulated the EMT at the translation level. Considering that the fibrosis of skin tissue will form scars, which is helpful for skin healing and has a certain protective effect, the inhibition of EMT of intestinal epithelial cells by AOPPs may be one of the reasons for IBD intestinal bleeding (30).

In conclusion, AOPPs promote apoptosis and inhibit the EMT of rat crypt epithelial cells, which may be associated with the inhibition of Akt phosphorylation and the promotion of p65 phosphorylation.

\section{Acknowledgements}

Not applicable.

\section{Funding}

The present study was supported by the Fujian Natural Science Foundation (grant no. 2016J01504).

\section{Availability of data and materials}

The datasets used and/or analyzed during the current study are available from the corresponding author on reasonable request.

\section{Authors' contributions}

YZ, JTZ, XYW, HXH and LXH performed the experiments and analyzed the data. YZ, LXH and CQZ designed the study and wrote the manuscript. All authors reviewed and approved the final manuscript.

\section{Ethics approval and consent to participate}

Not applicable.

\section{Patient consent for publication}

Not applicable.

\section{Competing interests}

The authors declare that they have no competing interests.

\section{References}

1. Witko-Sarsat V, Friedlander M, Capeillère-Blandin C, Nguyen-Khoa T, Nguyen AT, Zingraff J, Jungers P and Descamps-Latscha B: Advanced oxidation protein products as a novel marker of oxidative stress in uremia. Kidney Int 49: 1304-1313, 1996.

2. Wu Q, Zhong ZM, Pan Y, Zeng JH, Zheng S, Zhu SY and Chen JT: Advanced oxidation protein products as a novel marker of oxidative stress in postmenopausal osteoporosis. Med Sci Monit 21: 2428-2432, 2015

3. Witko-Sarsat V, Gausson V, Nguyen AT, Touam M, Drüeke T, Santangelo F and Descamps-Latscha B: AOPP-induced activation of human neutrophil and monocyte oxidative metabolism: A potential target for $\mathrm{N}$-acetylcysteine treatment in dialysis patients. Kidney Int 64: 82-91, 2003. 
4. Witko-Sarsat V, Friedlander M, Nouyen Khoa T, Capeillère-Blandin C, Nguyen AT, Canteloup S, Dayer JM, Jungers P, Drüeke T and Descamps-Latscha B: Advanced oxidation protein products as novel mediators of inflammation and monocyte activation in chronic renal failure. J Immunol 161 2524-2532, 1998.

5. Kaneda H, Taguchi J, Ogasawara K, Aizawa T and Ohno M: Increased level of advanced oxidation protein products in patients with coronary artery disease. Atherosclerosis 162: 221-225, 2002.

6. Zhou LL, Cao W, Xie C, Tian J, Zhou Z, Zhou Q, Zhu P, Li A, Liu Y, Miyata T, et al: The receptor of advanced glycation end products plays a central role in advanced oxidation protein products-induced podocyte apoptosis. Kidney Int 82: 759-770, 2012.

7. Liu Z, Yao X, Jiang W, Li W, Zhu S, Liao C, Zou L, Ding R and Chen $\mathrm{J}$ : Advanced oxidation protein products induce microglia-mediated neuroinflammation via MAPKs-NF- $\kappa$ B signaling pathway and pyroptosis after secondary spinal cord injury. J Neuroinflammation 17: 90, 2020.

8. Derkacz A, Olczyk P and Komosinska-Vassev K: Diagnostic markers for nonspecific inflammatory bowel diseases. Dis Markers 2018: 7451946, 2018.

9. Krzystek-Korpacka M, Neubauer K, Berdowska I, Boehm D, Zielinski B, Petryszyn P, Terlecki G, Paradowski L and Gamian A: Enhanced formation of advanced oxidation protein products in IBD. Inflamm Bowel Dis 14: 794-802, 2008.

10. Balmus IM, Ciobica A, Trifan A and Stanciu C: The implications of oxidative stress and antioxidant therapies in inflammatory bowel disease: Clinical aspects and animal models. Saudi J Gastroenterol 22: 3-17, 2016

11. Gunther C, Neumann H, Neurath MF and Becker C: Apoptosis, necrosis and necroptosis: Cell death regulation in the intestinal epithelium. Gut 62: 1062-1071, 2013.

12. Witko-Sarsat V, Nguyen-Khoa T, Jungers P, Drueke TB and Descamps-Latscha B: Advanced oxidation protein products as a novel molecular basis of oxidative stress in uraemia. Nephrol Dial Transplant 14 (Suppl 1): S76-S78, 1999.

13. Marsche G, Frank S, Hrzenjak A, Holzer M, Dirnberger S, Wadsack C, Scharnagl H, Stojakovic T, Heinemann A and Oettl K: Plasma-advanced oxidation protein products are potent high-density lipoprotein receptor antagonists in vivo. Circ Res 104: 750-757, 2009.

14. Zhu G, Li J, He L, Wang X and Hong X: MPTP-induced changes in hippocampal synaptic plasticity and memory are prevented by memantine through the BDNF-TrkB pathway. $\mathrm{Br}$ J Pharmacol 172: 2354-2368, 2015.

15. Livak KJ and Schmittgen TD: Analysis of relative gene expression data using real-time quantitative PCR and the 2(-Delta Delta C(T)) method. Methods 25: 402-408, 2001.

16. Sun S, Xie F, Zhang Q, Cui Z, Cheng X, Zhong F, He K and Zhou J: Advanced oxidation protein products induce hepatocyte epithelial-mesenchymal transition via a ROS-dependent, TGF-beta/Smad signaling pathway. Cell Biol Int 41: 842-853, 2017.

17. Schulzke JD, Ploeger S, Amasheh M, Fromm A, Zeissig S, Troeger H, Richter J, Bojarski C, Schumann M and Fromm M: Epithelial tight junctions in intestinal inflammation. Ann N Y Acad Sci 1165: 294-300, 2009
18. Low D, Mino-Kenudson M and Mizoguchi E: Recent advancement in understanding colitis-associated tumorigenesis. Inflamm Bowel Dis 20: 2115-2123, 2014

19. Xu X, Sun S, Xie F, Ma J, Tang J, He S and Bai L: Advanced oxidation protein products induce epithelial-mesenchyma transition of intestinal epithelial cells via a PKC delta-mediated, redox-dependent signaling pathway. Antioxid Redox Signal 27: 37-56, 2017.

20. Zhong ZM, Bai L and Chen JT: Advanced oxidation protein products inhibit proliferation and differentiation of rat osteoblast-like cells via NF-kappaB pathway. Cell Physiol Biochem 24: 105-114, 2009.

21. Yang SJ, Song ZJ, Wang XC, Zhang ZR, Wu SB and Zhu GQ Curculigoside facilitates fear extinction and prevents depression-like behaviors in a mouse learned helplessness mode through increasing hippocampal BDNF. Acta Pharmacol Sin 40: $1269-1278,2019$

22. Larue L and Bellacosa A: Epithelial-mesenchymal transition in development and cancer: Role of phosphatidylinositol 3 kinase/AKT pathways. Oncogene 24: 7443-7454, 2005.

23. Zhu G, Wang X, Wu S, Li X and Li Q: Neuroprotective effects of puerarin on 1-methyl-4-phenyl-1,2,3,6-tetrahydropyridine induced Parkinson's disease model in mice. Phytother Res 28 : 179-186, 2014.

24. Huber MA, Beug H and Wirth T: Epithelial-mesenchymal transition: NF-kappaB takes center stage. Cell Cycle 3: 1477-1480, 2004.

25. Song Z, Shen F, Zhang Z, Wu S and Zhu G: Calpain inhibition ameliorates depression-like behaviors by reducing inflammation and promoting synaptic protein expression in the hippocampus. Neuropharmacology 174: 108175, 2020.

26. Ma C, Huang S, Xu L, Tian L, Yang Y and Wang J: Transcription co-activator P300 activates Elk1-aPKC-iota signaling mediated epithelial-to-mesenchymal transition and malignancy in hepatocellular carcinoma. Oncogenesis 9: 32, 2020

27. Thiery JP and Sleeman JP: Complex networks orchestrate epithelial-mesenchymal transitions. Nat Rev Mol Cell Biol 7: 131-142, 2006.

28. MicalizziDS,FarabaughSMandFordHL:Epithelial-mesenchymal transition in cancer: Parallels between normal development and tumor progression. J Mammary Gland Biol Neoplasia 15: 117-134, 2010.

29. Gasiule S, Dreize N, Kaupinis A, Ražanskas R, Čiupas L, Stankevičius V, Kapustina Ž, Laurinavičius A, Valius M and Vilkaitis G: Molecular insights into miRNA-driven resistance to 5-fluorouracil and oxaliplatin chemotherapy: miR-23b modulates the epithelial-mesenchymal transition of colorectal cancer cells. J Clin Med 8: 2115, 2019.

30. Roda G, Sartini A, Zambon E, Calafiore A, Marocchi M, Caponi A, Belluzzi A and Roda E: Intestinal epithelial cells in inflammatory bowel diseases. World J Gastroenterol 16: 4264-4271, 2010 